\title{
\#SafeSport: safeguarding initiatives at the Youth Olympic Games 2018
}

\author{
Margo Mountjoy (1) , ${ }^{1,2}$ Tine Vertommen, ${ }^{3,4}$ Kirsty Burrows, ${ }^{5}$ Susan Greinig ${ }^{5}$
}

${ }^{1}$ Family Medicine, McMaster University Michael G DeGroote School of Medicine, Hamilton, Ontario, Canada

${ }^{2}$ Sports Medicine, FINA Bureau, Lausanne, Switzerland

${ }^{3}$ Medicine and Health Sciences, Universiteit Antwerpen, Antwerpen, Belgium

${ }^{4}$ Applied Psychology, Thomas More University of Applied Sciences, Mechelen, Belgium Medical and Scientific Department, International Olympic Committee, Lausanne, Switzerland

\section{Correspondence to} Dr Margo Mountjoy, Family Medicine, McMaster University Michael G DeGroote School of Medicine, Hamilton, ON L8S 4K1, Canada;

mountjm@mcmaster.ca

Accepted 14 November 2019 Published Online First

2 December 2019
Check for updates

(C) Author(s) (or their employer(s)) 2020. No commercial re-use. See rights and permissions. Published by BMJ.

To cite: Mountjoy $M$ Vertommen T, Burrows K et al. Br J Sports Med 2020:54:176-182.

\section{ABSTRACT}

Background Little is known about athletes' understanding of safe sport and occurrence of harassment and abuse in elite youth sport.

Objective To evaluate the IOC Safe Sport educational experience at the Youth Olympic Games 2018 in Buenos Aires and to ascertain the athletes' (1) understanding of what constitutes harassment and abuse, (2) perception of the occurrence in their sport, and (3) knowledge of where to report.

Methods Athletes visiting the IOC Safe Sport Booth answered a survey related to athletes' (1) understanding of harassment and abuse in sport, (2) perception of the occurrence of harassment and abuse in their sport, and (3) knowledge of where to report. Experts and volunteers answered an email survey on their experience.

Results The response rate was $71.8 \%$. When asked to define 'safe sport', the athletes mainly relate the concept to general physical and environmental safety, fair play and clean sport, rather than sport free from harassment and abuse. Almost half (46\%) of the athletes expressed surprise by the definition of behaviours of harassment and abuse within sport. When asked if harassment and/ or abuse occur in their sport, $47.5 \%$ reported 'no' or 'not likely', while $34 \%$ stated 'likely' or 'very likely'; $19 \%$ were 'unsure'. The majority (63\%) of athletes knew where to seek help. Three quarters $(71 \%)$ of the athletes rated the educational materials as 'good' to 'excellent'. The experts and volunteers believed the intervention would result in change in athletes' awareness, knowledge and behaviour.

Conclusions This multinational cohort of elite youth athletes is not knowledgeable of the concept of harassment and abuse in sport, despite there being a significant perception of occurrence of harassment and abuse in their sports.

\section{INTRODUCTION}

At the IOC, and at the Youth Olympic Games, our role is to promote safe sport and take action to protect athletes from all forms of harassment and abuse. While sport is global, crossing cultures and law, only one culture applies-and that is one of RESPECT. ${ }^{1}$

According to the Fundamental Principles outlined in the Olympic Code of Ethics (2016), ${ }^{2}$ all athletes have the right to safe sport, which rejects '... all forms of harassment and abuse, be it physical, professional or sexual, and any physical or mental injuries'. This premise is also embedded in the Olympic Agenda 2020 which recommends the IOC strengthen support to athletes both during and outside of the Olympic Games (Recommendation No 18), ${ }^{3}$ and in the International Athletes Forum which explicitly recommends the development of educational materials on issues of athlete welfare including the prevention harassment and abuse in sport (recommendation $2 \mathrm{~d}$ ). ${ }^{4}$ The IOC convened its first consensus meeting on sexual harassment and abuse in sport in $2006^{5}$ which was updated to include all forms of harassment and abuse in $2016 .{ }^{6}$ With respect to activation of the principles outlined in the consensus statements, the IOC first introduced a Safeguarding Framework for the Olympic Games (2016) in Rio de Janeiro, Brazil.

The Youth Olympic Games (YOG) for athletes aged 15-18 years was first introduced in 2010 in Singapore. While all editions of the YOG have included educational materials on Safe Sport, modifications were made for the 2018 edition of the YOG held in Buenos Aires, Argentina, to be more specific for youth athletes. The Athlete365 Space, Buenos Aires, was located in the Village Square of the Youth Olympic Village to facilitate ease of access, as part of the wider Youth Olympic Games Athlete365 Education Programme. There were five educational initiatives at the Athlete365 Space, Buenos Aires Learn and Share Centre: (1) antidoping, (2) anticompetition manipulation, (3) postcareer learning opportunities, (4) Olympic Solidarity, and (5) the Safe Sport Booth. The Safe Sport Booth was designed following consultation with survivors of harassment and abuse. It was staffed by seven international experts (engaged professionally in the field of safeguarding), including two experts by experience (survivors of sexual abuse in sport), and six volunteers, who wore branded \#SafeSport t-shirts for ease of identification. Access to mental health support through the local medical services was available at the medical clinic in the Youth Olympic Village. Sunglasses marked with the dedicated hotline and email address reporting mechanisms as well as links to educational materials on the IOC Athlete365 YOG web pages (see table 1) were given as an incentive for participation. ${ }^{7}$ One of the activities was a 'Pledge', where the participants received a souvenir photograph of themselves pledging to adhere to the values of safe sport (figure 1). In addition, there were two educational programmes on tablets at the Safe Sport Booth:

1. A 'Draw the Line' scenario-based educational tool intended to assist athletes to identify moral and ethical boundaries, and to recognise various forms of harassment and abuse. It is available in English, Spanish, French and Russian. Embedded in this tool was an athlete survey. ${ }^{7}$

2. An animation film designed to raise awareness of the different forms of harassment and abuse, and to identify resources for further information and assistance. ${ }^{8}$ 
Table 1 Resources on Safe Sport found on the IOC-YOG web pages: 'you have the right to respect and safety!"1

\begin{tabular}{|c|c|}
\hline Introductory information & $\begin{array}{l}\text { Harassment and abuse definitions } \\
\text { Culture of respect }\end{array}$ \\
\hline Report it link & To the Integrity and Compliance Hotline \\
\hline Make your voice heard & $\begin{array}{l}\text { Scenarios and information on sexual harassment } \\
\text { and abuse }\end{array}$ \\
\hline \#Learning Online Course & $\begin{array}{l}\text { Four lessons: } \\
\text { 1. What is harassment + abuse? (11 } \mathrm{min}) \\
\text { 2. Recognising the signs ( } 10 \mathrm{~min}) \\
\text { 3. Understanding your role }(13 \mathrm{~min}) \\
\text { 4. What can organisations do? (9 min) } \\
\text { Links to a quiz } \\
\text { Athlete insights } \\
\text { Community discussion } \\
\text { Suggested readings }\end{array}$ \\
\hline Draw the Line & - Educational video and quiz \\
\hline \#SafeSport: Find out more & - An athlete's guide to safe sport introduction video \\
\hline Female athlete health & - Video link to online learning course \\
\hline Health body image & - Video link to four scenario-based learning videos \\
\hline
\end{tabular}

YOG, Youth Olympic Games.

International Federations also held educational Focus Days in the Youth Olympic Village. Federation Internationale de Natation (swimming and diving) included social media safety/cyberbullying in their agenda, and the Badminton Federation included an overview of harassment and abuse in sport.

Another modification to the implementation of the Safeguarding Strategy for the YOG 2018 was the YOG Framework for Safeguarding Athletes which was developed to clarify the

\section{ATHLETE PLEDGE}

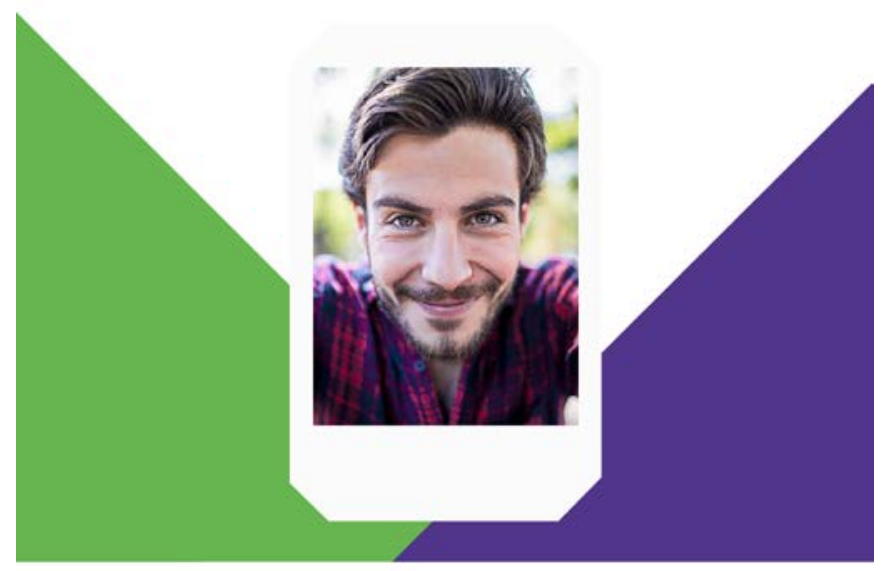

I. PEDRO

PLEDGE TO:

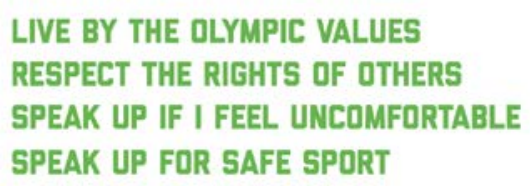

\#SAFE

SPORT

Figure 1 Athlete and entourage pledge for safe sport. policy and procedures for the prevention, reporting and management of incidents of harassment and abuse. ${ }^{9}$

As the safeguarding initiative at the YOG 2018 was a new programme, the objectives of this study were to evaluate the IOC Safe Sport educational experience at the YOG 2018 from the perspectives of the athletes and support staff, and to ascertain the athletes' (1) understanding of harassment and abuse, (2) perception of prevalence in their sport, and (3) knowledge of reporting.

\section{METHODS}

All athletes registered at the YOG 2018 were encouraged to participate in the online survey which was found at the Safe Sport Booth. This survey was developed by the IOC Safeguarding Officer and an external consultant in collaboration with the IOC Games Department. The study period was from the opening of the Youth Olympic Games Athlete365 Education Programme in the Youth Olympic Village on 2 October, to the closing of the Youth Olympic Village on 18 October 2018.

Following the YOG, the seven experts (including two experts by experience) and six volunteers who worked in the Safe Sport Booth were invited by email sent from the IOC to respond to an online questionnaire about their experience and observations. A reminder email was sent to encourage participation 2 weeks later. The two experts by experience also engaged in a semistructured Skype interview with one member of the research team (TV) in order to gather their personal feedback about their experience at the YOG 2018.

Frequency and cross tables are used to present the data. $\chi^{2}$ tests were used to compare athlete groups based on the survey language (English, Spanish, French) and type of sport (team vs individual sport). The significance level was set at 5\%. Statistical analyses were performed using IBM SPSS V.25 software. To investigate athletes' interpretations of the term 'safe sport', thematic analysis was applied. Coding was performed by two independent researchers.

\section{RESULTS}

Athletes' feedback on safe sport and educational materials Response rate

Of the total number of athlete participants at the YOG $(n=3980)$, 1873 tapped their electronic identification badge (known as a 'YOGGER') to indicate their attendance at the Safe Sport Booth. The recorded visiting rate is at least $47 \%$, recognising that some athletes may not have registered with their YOGGER. A total of 1463 responses were gathered from the online survey, of which 1254 came from athletes, and the remaining 209 from members of entourage. The athlete survey response rate was $71.8 \%$ (table 2). About two-thirds of the athletes $(n=864 ; 68.9 \%)$ completed the English version of the questionnaire, a quarter chose the Spanish version $(n=320 ; 25.5 \%)$ and the remaining $5.5 \%(n=70)$ used the French version.

Athletes' understanding of safe sport, harassment and abuse The athletes were asked to describe their understanding of what 'safe sport' meant to them. A total of 1243 responses were gathered. Most responses related to general safety in sport, fair play, clean sport and sportsmanship (table 3). Only about $10 \%$ of responses referred to sport free from harassment and abuse. Examples of these athlete quotes are: 'Having sport practiced to the benefit of everyone and avoid harming anyone physically, socially and psychologically'; 'A safe space for me'; and 'It means to me that every sport should be appropriate enough to not bring 
Table 2 Athlete population per sport discipline at YOG 2018 and the number of collected responses to the survey

\begin{tabular}{|c|c|c|c|}
\hline $\begin{array}{l}\text { Sport } \\
\text { discipline }\end{array}$ & $\begin{array}{l}\text { Total population } \\
\text { competing at YOG }\end{array}$ & $\begin{array}{l}\text { Portion of the total } \\
\text { athlete population }\end{array}$ & $\begin{array}{l}\text { Survey responses, } \\
\mathbf{n}\end{array}$ \\
\hline Aquatics & 426 & 10.7 & 135 \\
\hline Archery & 64 & 1.6 & 29 \\
\hline Athletics & 697 & 17.5 & 256 \\
\hline Badminton & 63 & 1.6 & 32 \\
\hline Basketball & 159 & 4.0 & 64 \\
\hline Beach handball & 216 & 5.4 & 72 \\
\hline Beach volleyball & 128 & 3.2 & 40 \\
\hline Boxing & 82 & 2.1 & 16 \\
\hline Canoeing & 63 & 1.6 & 20 \\
\hline Cycling & 125 & 3.1 & 35 \\
\hline Dance sport & 24 & 0.6 & 3 \\
\hline Equestrian & 30 & 0.8 & 4 \\
\hline Fencing & 78 & 2.0 & 25 \\
\hline Field hockey & 216 & 5.4 & 63 \\
\hline Futsal & 199 & 5.0 & 32 \\
\hline Golf & 64 & 1.6 & 9 \\
\hline Gymnastics & 154 & 3.9 & 58 \\
\hline Judo & 104 & 2.6 & 36 \\
\hline Karate & 48 & 1.2 & 9 \\
\hline $\begin{array}{l}\text { Modern } \\
\text { pentathlon }\end{array}$ & 48 & 1.2 & 12 \\
\hline $\begin{array}{l}\text { Roller speed } \\
\text { skating }\end{array}$ & 28 & 0.7 & 7 \\
\hline Rowing & 96 & 2.4 & 52 \\
\hline Rugby sevens & 143 & 3.6 & 29 \\
\hline Sailing & 99 & 2.5 & 28 \\
\hline Shooting & 80 & 2.0 & 32 \\
\hline Sport climbing & 42 & 1.1 & 10 \\
\hline Table tennis & 65 & 1.6 & 10 \\
\hline Taekwondo & 99 & 2.5 & 27 \\
\hline Tennis & 64 & 1.6 & 8 \\
\hline Triathlon & 64 & 1.6 & 18 \\
\hline Weightlifting & 102 & 2.6 & 23 \\
\hline Wrestling & 110 & 2.8 & 36 \\
\hline Sport unknown & & & 24 \\
\hline Total & 3980 & 100.00 & 1254 \\
\hline
\end{tabular}

Since no data were collected on the total number of Safe Sport visitors per sport discipline, it is impossible to calculate a response rate per discipline. It is likely that some athletes visited the Booth but did not participate in the survey. YOG, Youth Olympic Games.

any form of harassment and abuse'. Less than $1 \%$ were unaware of the concept or had a negative perception.

The athletes were also asked whether the listed behaviours constituted harassment or abuse. The majority of athletes correctly identified bullying, sexual harassment and abuse, forced use of doping or supplements, training in unsafe environments, cyberbullying and inappropriate training (table 4). Less than half identified training when injured, sick or exhausted as harassment or abuse. When asked to describe other behaviours that constitute harassment or abuse, 24 responses were collected, including being pressured by sport managers, harassment based on religious beliefs, training with less tools, verbal abuse, favouritism, corruption and gossip.

When the athletes were prompted that all listed behaviours are forms of harassment and abuse, $46 \%(n=578)$ indicated surprise at this fact. Significantly more Spanish-speaking athletes were surprised (56.6\%), in comparison with French-speaking (47.1\%) and English-speaking athletes $(42.8 \%)\left(\chi^{2}=17.780, \mathrm{p}<0.005\right)$. No difference was found when comparing team with individual sports.

Athletes' perception of the occurrence of harassment and abuse in their sport

Almost half of the athletes reported that harassment and abuse was 'not' or 'not likely' happening in their sport, while almost $35 \%$ stated that harassment and abuse 'likely' or 'very likely' occurs in their sport (table 4). Significantly more Spanishspeaking athletes reported that harassment and abuse did not occur in their sport (37\%), in comparison with 32\% in Frenchspeaking and $27 \%$ in English-speaking athletes $\left(\chi^{2}=23.696\right.$, $\mathrm{p}<0.005)$. No difference was found when comparing individual versus team sport athletes. When asked whether the athlete knew where to go when feeling uncomfortable or if they had witnessed something that made him/her concerned for someone else's welfare, almost $63 \%$ reported knowing where to seek help, $11 \%$ were unaware of what to do, 21\% responded 'maybe' and almost $5 \%$ of athletes indicated that they would not feel comfortable to speak about it. Significantly more Spanish-speaking athletes indicated that they knew where to go for help (76\%) in comparison with French-speaking (63\%) and English-speaking athletes $(58 \%)\left(\chi^{2}=45.324, \mathrm{p}<0.005\right)$. The proportion of athletes not knowing where to go or not feeling comfortable to speak about it was similar in all three groups. No differences were found when comparing team versus individual sport athletes.

\section{Athletes' perception of the Safe Sport educational materials}

Three-quarters of the athletes who answered the survey stated that they participated in the education materials at the Safe Sport Booth. More than 71\% identified the tools as 'good', 'very good' or 'excellent'. About $18 \%$ of athletes reported that they were 'OK' and just over $10 \%$ of athletes 'did not like or understand them'.

\section{Experts and volunteers' perceptions and feedback}

We collected feedback from five safeguarding experts: two women, aged 45-64 years, and three men, aged 35 to $65+$ years. The experts reported that they received none or very little specific briefing other than a preparatory Skype meeting with the organisers before staffing the Safe Sport Booth. Additionally, feedback from three volunteers was gathered: two males aged 18-24 years (a student and a physical education teacher), and a female English teacher aged 25-34 years. They worked 6, 7 and 12 days as a volunteer at the Safe Sport Booth. They received an online briefing on the educational programme prior to the YOG. Table 5 illustrates the experts and volunteers' perception of the Safe Sport educational materials and their observations of the athletes' engagement with the tools.

All experts and volunteers believed that athlete participation in the Safe Sport Booth would result in change in athlete awareness, knowledge and behaviour with regard to safe sport. While working in the Safe Sport Booth, they reported that they received positive athlete comments, answered athlete questions and engaged in discussions. Some athletes returned to the booth with other athletes, to have another look at the material. They stated that for many athletes, the information on harassment and abuse was novel. In preparation for future editions, experts and volunteers recommended (1) the inclusion of more language options in the education materials to enhance athlete comprehension, (2) the provision of a more private, designated area for 
Original research

Table 3 Athletes' perception of the term 'Safe Sport'

\begin{tabular}{|c|c|c|c|c|}
\hline Theme/subtheme & Count & $\%$ of total & Example 1 & Example 2 \\
\hline Safety & 271 & 21.8 & & \\
\hline General safety & 152 & & 'When sports are played safely' & $\begin{array}{l}\text { 'Means that there are precautions taken to make } \\
\text { your sport safer' }\end{array}$ \\
\hline Free from harm & 65 & & 'Free of harm...' & 'Not doing things that can harm you or others' \\
\hline Feeling safe & 25 & & $\begin{array}{l}\text { 'That you can do sports without you feeling unsafe } \\
\text { in any way' }\end{array}$ & 'It means feeling safe while doing sports' \\
\hline Safe environment & 21 & & 'That we play in a safe environment...' & 'It means a safe environment for all athletes' \\
\hline Safety equipment & 8 & & 'Life jacket' & $\begin{array}{l}\text { 'Participate with the necessary equipment and } \\
\text { appropriate safety' }\end{array}$ \\
\hline Fair play & 236 & 19.0 & & \\
\hline Following the rules & 135 & & 'Playing by the rules and not playing dirty' & 'To follow the rules and be a right athlete' \\
\hline Clean sport & 101 & & 'Clean and Fair' & 'No doping' \\
\hline Positive association & 119 & 9.6 & & \\
\hline $\begin{array}{l}\text { Elicitation of a positive emotion/ } \\
\text { feeling }\end{array}$ & 47 & & 'So lovely' & 'Joy' \\
\hline Positive noun & 32 & & 'spiritual peace' & 'Passion' \\
\hline Positive adjective & 25 & & '...humble sport' & 'Good' \\
\hline Freedom & 15 & & 'It means actually being free in the sport u do...' & 'To be free and happy without any problem' \\
\hline Free from harassment and/or abuse & 118 & 9.5 & 'Sport free from harassment and abuse' & 'No harassing and abuse' \\
\hline Sportsmanship & 103 & 8.3 & & \\
\hline Respect & 50 & & 'It means respecting each other' & $\begin{array}{l}\text { 'Respect each other and everyone is nice to each } \\
\text { another. And remember we are only humans' }\end{array}$ \\
\hline $\begin{array}{l}\text { Adherence to moral/ethical } \\
\text { principles }\end{array}$ & 29 & & 'Doing the right things' & 'Staying true to the sport' \\
\hline Sportsmanship & 14 & & '...having good sportsmanship' & $\begin{array}{l}\text { '...Having a common understanding of the sport } \\
\text { and displaying sportsmanship' }\end{array}$ \\
\hline Equality & 10 & & '...tolerance' & 'Play with all' \\
\hline Health and wellness & 82 & 6.6 & & \\
\hline Injury free & 42 & & 'Sport without injuries' & 'Playing without injuries' \\
\hline Related to health and wellness & 34 & & $\begin{array}{l}\text { 'It means I feel physically and mentally well when } \\
\text { I do sport' }\end{array}$ & $\begin{array}{l}\text { 'Enjoy the game and at the same time take care } \\
\text { of myself' }\end{array}$ \\
\hline $\begin{array}{l}\text { Personal growth and } \\
\text { development }\end{array}$ & 6 & & 'Sport makes you a good person' & $\begin{array}{l}\text { 'Good means a passion for what you do is have } \\
\text { a goal in life proposed something which want to } \\
\text { reach for a future' }\end{array}$ \\
\hline Free from discomfort, worry or fear & 43 & 3.5 & $\begin{array}{l}\text { 'When you can practice sport freely without feeling } \\
\text { awkward or afraid' }\end{array}$ & '...Sporting without any worries or so' \\
\hline Supportive environment & 42 & 3.4 & & \\
\hline Supportive environment & 23 & & $\begin{array}{l}\text { 'Support and encourage people to make sport! Help } \\
\text { people in their practice and help them to preserve } \\
\text { their selves' }\end{array}$ & 'Having great atmosphere where to train...' \\
\hline Quality training & 11 & & 'Training safe and smart' & 'Training the correct and sensible way' \\
\hline Unity and teamwork & 5 & & 'The team is more united...' & 'One team' \\
\hline Social & 3 & & $\begin{array}{l}\text { 'For me to be athletes is a wonderful addition to the } \\
\text { many travel to different parts of the world, meeting } \\
\text { new friends and leaving us with our satisfying } \\
\text { results' }\end{array}$ & 'Means have good relaciones' \\
\hline Statement of importance & 40 & 3.2 & 'It means very much to me' & $\begin{array}{l}\text { 'It is something what every athlete should know } \\
\text { and do everything for swing it' }\end{array}$ \\
\hline Other & 32 & 2.6 & & \\
\hline Performance-related response & 15 & & 'Success' & 'Win' \\
\hline Other & 9 & & 'constant sport' & '...progress' \\
\hline Growing the sport & 6 & & $\begin{array}{l}\text { 'It means we should do to help sport grow and } \\
\text { increase the number of athletes around the world' }\end{array}$ & 'To expand the sport' \\
\hline Quality facilities & 2 & & '...facilities are in good condition' & $\begin{array}{l}\text { 'Best center really far from doping and move away } \\
\text { from all that...' }\end{array}$ \\
\hline Not aware of the term & 5 & 0.4 & 'I do not know' & 'Nothing' \\
\hline Negative perception of safe sport & 3 & 0.2 & 'We don't have safe sport in...' & 'Not cool' \\
\hline Invalid or unrelated response & 149 & 12.0 & 'player futsal' & '2iu' \\
\hline Total codes & 1243 & 100.0 & & \\
\hline
\end{tabular}


Table 4 Athletes' perception of safe sport and the occurrence of harassment and abuse in their sport

n $\quad \%$

Number of athletes who recognise the behaviours as forms of harassment and abuse

\begin{tabular}{|c|c|c|}
\hline Bullying & 923 & 73.6 \\
\hline Sexual harassment & 828 & 66.0 \\
\hline Sexual abuse & 820 & 65.4 \\
\hline Forced doping/supplements & 803 & 64.0 \\
\hline Physical abuse & 800 & 63.8 \\
\hline Training in an unsafe environment & 771 & 61.5 \\
\hline Cyberbullying & 756 & 60.3 \\
\hline Inappropriate training & 651 & 51.9 \\
\hline Training when injured, sick or exhausted & 521 & 41.5 \\
\hline Other & 24 & 1.9 \\
\hline \multicolumn{3}{|c|}{$\begin{array}{l}\text { All of the things listed in the previous questions were } \\
\text { forms of harassment and abuse. } \\
\text { Does this surprise you? }\end{array}$} \\
\hline Yes & 578 & 46.1 \\
\hline No & 663 & 52.9 \\
\hline \multicolumn{3}{|c|}{$\begin{array}{l}\text { Do you think harassment and abuse occurs in your } \\
\text { sport? }\end{array}$} \\
\hline No & 375 & 30.3 \\
\hline Not likely & 213 & 17.2 \\
\hline Not sure & 235 & 19.0 \\
\hline Likely & 302 & 24.4 \\
\hline Very likely & 113 & 9.1 \\
\hline
\end{tabular}

'one on one' time with athletes, (3) the enhancement of volunteer training prior to the event, and (4) the correction of technical issues, such as access to Wi-Fi and more tablets.

\section{DISCUSSION}

According to the United Nations, youth athletes, defined as being 18 years of age or younger, have the fundamental right to participate in sport. ${ }^{10}$ The IOC's 2008 consensus statement on Training the Elite Child Athlete states that '...the entire sports process for the elite child athlete should be pleasurable and fulfilling." 11 Youth athletes, being in a period of critical transition, ${ }^{12}$ are particularly vulnerable to harassment and abuse, ${ }^{6}$ thus necessitating the development of a sport culture and environment that is 'enjoyable, safe, healthy, and sustainable'. ${ }^{8}$ These principles emphasise the importance of ensuring that youth athletes are protected from harassment and abuse during their sporting experience, ${ }^{13}$ and provide the underlying premise for the implementation of the safeguarding initiatives at the YOG 2018. Specifically, the YOG offers a unique opportunity to implement an educational programme in safeguarding, and to conduct a survey to ascertain athletes' understanding of harassment and abuse, their knowledge of reporting mechanisms and their perception of occurrence. This is the first study in the field of harassment and abuse in a large cohort of youth athletes from 206 countries in 32 Olympic sport disciplines.

\section{Athletes' knowledge of safe sport}

Athletes participating in the online survey demonstrated a lack of understanding of the term 'safe sport'. When asked to define 'safe sport', athletes provided a variety of responses related to health, antidoping and the integrity of sport. When prompted to identify if various behaviours were forms of harassment and abuse, the results show that the athlete respondents were largely unaware of the various ways in which harassment and abuse can occur within the sporting context. In addition, almost half $(46.1 \%)$ of the participating athletes reported surprise on learning of the various forms of harassment and abuse, and only

\begin{tabular}{|c|c|c|}
\hline Tool & Experts $(n=5)$ & Volunteers $(n=3)$ \\
\hline \multicolumn{3}{|l|}{ Draw the Line video and quiz } \\
\hline Was this activity appropriate for the age of the athlete? & 5 Yes & 1 Yes, 2 Not sure \\
\hline Was it appropriate for the subject material? & 5 Yes & 3 Yes \\
\hline Did the athletes seem to engage with this activity? & $4 / 5$ Yes, $1 / 5$ Not sure & 3 Yes \\
\hline Do you have any observations of the athletes' response to this activity? & $\begin{array}{l}\text { Some seemed very interested, others were skipping } \\
\text { through as fast as possible. }\end{array}$ & Some seemed very interested, others not. \\
\hline \multicolumn{3}{|l|}{ Athlete and entourage safe sport pledge } \\
\hline Was this activity appropriate for the age of the athlete? & 5 Yes & 3 Yes \\
\hline Was it appropriate for the subject material? & 5 Yes & 3 Yes \\
\hline Did the athletes seem to engage with this activity? & $4 / 5$ Yes, $1 / 5$ Not sure & 3 Yes \\
\hline Do you have any observations of the athletes' response to this activity? & $\begin{array}{l}\text { Positive, but some athletes seemed to be more } \\
\text { interested to take the included profile picture than to } \\
\text { learn anything. }\end{array}$ & Athletes were interested. \\
\hline \multicolumn{3}{|l|}{ Video on maladapted training, cyberbullying and sexual abuse } \\
\hline Was this activity appropriate for the age of the athlete? & 4 Yes, 1 Not sure & 2 Yes, 1 Not sure \\
\hline Was it appropriate for the subject material? & 4 Yes, 1 Not sure & 2 Yes, 1 Don't know \\
\hline Did the athletes seem to engage with this activity? & 3 Yes, 2 Not sure & 3 Yes \\
\hline Do you have any observations of the athletes' response to this activity? & Could be better, difficulties with connection & $\begin{array}{l}\text { Some athletes watched the movie in order } \\
\text { to earn points. }\end{array}$ \\
\hline \multicolumn{3}{|l|}{ Survey } \\
\hline Was this activity appropriate for the age of the athlete? & 5 Yes & 2 Yes, 1 Not sure \\
\hline Was it appropriate for the subject material? & 5 Yes & 2 Yes, 1 Don't know \\
\hline Did the athletes seem to engage with this activity? & 4 Yes, 1 Not sure & 3 Yes \\
\hline Do you have any observations of the athletes' response to this activity? & Technical and language barriers & \\
\hline
\end{tabular}


$63 \%$ knew where to go for help should they personally experience or witness harassment and abuse during sport participation. It is evident that this cohort of elite youth athletes from around the world had a poor understanding of the concept of harassment and abuse in sport. This knowledge gap can most likely be attributed to their lack of exposure to educational initiatives on the subject. While it is possible that the knowledge gap exists as a result of naiveté from a lack of exposure to harassment and abuse in their sport, the prevalence data obtained in this study and in the scientific literature, however, refute this theory. These findings underscore the need to develop validated intervention strategies targeted for elite youth athletes to increase their understanding of harassment and abuse in sport.

\section{Prevalence of harassment and abuse in elite youth sport}

Following exposure to the educational materials outlining what constitutes harassment and abuse in sport, athletes were asked to identify if harassment and abuse occurs in their sport. Almost $34 \%$ of participating athletes reported that harassment and abuse either 'very likely' or 'likely' occurs in their sport, and that a further $19 \%$ were 'unsure'. This finding is consistent with published studies that found an increased risk of harassment and abuse in youth athletes competing at international level. ${ }^{14-16}$ In particular, a self-report survey in UK students identified the prevalence of other forms of abuse in this age cohort of emotional harm $(75 \%),{ }^{17} 18$ sexual harassment $(29 \%)$ and physical harm (24\%). ${ }^{17}$ A retrospective study of youth athletes in the Netherlands and Belgium reported the prevalence for psychological violence $(38 \%)$, sexual violence $(14 \%)$ and physical violence $(11 \%)$. This cross-sectional study revealed that sport performance level was positively correlated with a higher prevalence of all types of harassment and abuse. ${ }^{16} \mathrm{~A}$ limitation of the survey methodology in the Safe Sport educational programme is that it did not require the athletes to report the type of abuse. While there are no publications on the prevalence of harassment and abuse in youth sport from a large, multinational cohort, there are prevalence studies on sexual abuse in this age group of athletes from the UK (3\%), ${ }^{17}$ Denmark $(2 \%)^{19}$ and Australia $(9.7 \%) .{ }^{20}$ Comparison of prevalence estimates, however, is challenging due to a lack of standardised methodological designs and definitions used in this area of research, as well as low response rates in some of the published studies. More epidemiological research with standardised methodology is required to better define and compare the prevalence of the various forms of harassment and abuse in youth sport in the Olympic sport disciplines among the diverse geographical and cultural regions of the world. The data on perception of occurrence identified in this study highlight the necessity to implement policies and procedures to prevent and manage allegations of harassment and abuse in elite youth sport as outlined in the IOC consensus statement (2016). ${ }^{6}$ Behaviours that are not acceptable in sport should be explicitly defined in behavioural codes of conduct for all members of the athlete entourage. In a framework evaluating risks to youth athletes, these unacceptable behaviours are referred to as 'athlete threats', and can be categorised into individual, relational or organisational threats. ${ }^{21}$ To develop robust prevention interventions, the International Safeguards for Children in Sport have identified eight specific safeguarding components ${ }^{22}$ :

1. Developing your policy.

2. Procedures for responding to safeguarding concerns.

3. Advice and support.

4. Minimising risks to children.

5. Guidelines for behaviour.
6. Recruiting, training and communicating.

7. Working with partners.

8. Monitoring and evaluating.

\section{Safe Sport Booth}

Sport organisations hosting large international multisport youth events can benefit from the evaluation of the Safe Sport Booth initiative implemented at the YOG 2018. It is encouraging that almost three-quarters $(72 \%)$ of the participating athletes rated the educational tools as being 'good' to 'excellent' demonstrating that athletes in this age group are receptive to the learning tools and style implemented at an elite sporting competition. As well, the experts and volunteers reported that the educational tools were well designed, age appropriate, relevant for the subject matter and engaging for the target audience. Ensuring adequate numbers of tablets, reliability of the Wi-Fi as well as providing translation of the educational materials into more languages would improve athletes' understanding of the material and ultimately the effectiveness of the intervention.

The volunteers and experts reported their experience at the Safe Sport Booth as being valuable and enjoyable; and all reported a willingness to volunteer for a similar intervention in the future. Given the potential sensitivity of the subject matter, implementing mandatory, robust volunteer training in the area of managing disclosures of abuse, and supporting individuals in crisis is a priority to ensure athlete safety. In addition, if using 'experts by experience' in the delivery of the intervention, sensitivity and professional support is required for those who may be triggered by trauma-related responses to the activities. When designing the physical space, provision should be made for an easily accessible, safe, private space with low sensory stimulation for potential disclosures and/or for support of individuals in distress.

In order to demonstrate and evaluate the effectiveness of any safeguarding initiative, we recommended the use of a systematic theoretical evaluation model, such as the Re-Aim framework which assesses five components (ㄹeach, Effectiveness, $\underline{\text { Adoption, }}$ Implementation and Maintenance) that evaluate the feasibility and translatability of the intervention. ${ }^{2324}$ Employing a theoretical framework to evaluate interventions will identify strengths and weaknesses to inform future programme modifications thus improving effectiveness.

\section{CONCLUSIONS}

The fundamental principles of Olympism outlined in the Olympic Charter state that:

The practice of sport is a human right. Every individual must have the possibility of practicing sport without discrimination of any kind...such as race, colour, sex, sexual orientation, language, religion, political or other opinion, national or social origin, property, birth or other status. ${ }^{25}$

The safeguarding initiative implemented at the YOG 2018 exemplifies the sentiments outlined in the Olympic Charter. Recommendations from this analysis should serve to influence future editions of the YOG, as well as other international youth multisport events. There is an urgent need to evaluate the effectiveness of interventions designed to promote \#SafeSport. Adoption of youth-oriented interventions to realise the goal of protecting athletes from all forms of harassment and abuse in sport will help sport organisations to create a safe and inclusive culture for all participants: 'Competing in an environment where you only have to worry about performance' (Unidentified YOG 2018 athlete). 


\section{What are the findings?}

- Education on safe sport during major events is feasible and requires coordination within safeguarding policies and procedures.

- Forty-six per cent of all responding athletes were unaware of what constitutes harassment and abuse in sport and 34\% reported that harassment and abuse likely or very likely occurs in their sport.

- Thirty-seven per cent of all responding athletes were either uncomfortable to or did not know where to report harassment or abuse.

\section{How might it impact on clinical practice in the future?}

- Education programmes on safe sport at large multisport youth events can model the Youth Olympic Games 2018 experience.

- Given the athletes' perception of occurrence of harassment and abuse in a cohort of multisport, multinational elite youth athletes, educational initiatives should occur early in a sport career.

- Harassment and abuse should be prevented in all elite (Olympic and non-Olympic) youth sport events.

Twitter Margo Mountjoy @margo.mountjoy, Tine Vertommen @TineVertommen and Kirsty Burrows @Kirsty_Burrows1

Acknowledgements We greatly appreciate the cooperation of the athletes attending the Youth Olympic Games who provided data for this project, the volunteers, IOC staff and experts who worked in the Safe Sport Booth, and the IOC for supporting the concept and logistics of the event. Finally, a sincere thank you to Rebecca Klimo, MD Candidate, for her kind assistance with coding.

\section{Collaborators Rebecca Klimo.}

Contributors MM: first author, substantial contributions to the conception and design of the review, interpretation of data. TV: second author, substantial contributions to the conception and design of the review, analysis and interpretation of data. MM and TV were involved in drafting, writing and revising of the manuscript, and final approval of the version to be published. All authors agree to be accountable for all aspects of the work in ensuring that questions related to the accuracy or integrity of any part of the work are appropriately investigated and resolved.

Funding The safeguarding initiative at the Youth Olympic Games 2018 in Buenos Aires, Argentina, was funded and delivered by the IOC, Lausanne, Switzerland.

\section{Competing interests None declared.}

Patient and public involvement statement Athletes were not involved in planning the research priorities, research questions, outcome measures, study design or conduct. There has been some discussion with the editors (including Karim Khan, Tracy Blake and Osman Ahmed) about how to describe the engagement with the athlete. Athletes from the IOC Athletes Commission will be informed of the results to use in their outreach programmes relating to harassment and abuse in sport. The results will inform the development of programmes for future editions of the Youth Olympic Games.

\section{Patient consent for publication Not required.}

Ethics approval The present concept and design was submitted to McMaster University-Hamilton Integrated Research Ethics Board, Canada. Ethical approval was not deemed necessary for this study given the embedded levels of strict confidentiality.

Provenance and peer review Not commissioned; externally peer reviewed.

Data availability statement All data relevant to the study are included in the article or uploaded as supplementary information.

\section{ORCID iD}

Margo Mountjoy http://orcid.org/0000-0001-8604-2014

\section{REFERENCES}

1 International Olympic Committee. YOG safe sport: you have the right to respect and safety! Available: https://www.olympic.org/athlete365/safe-sport-yog/ [Accessed 31 Dec 2018].

2 International Olympic Committee. IOC code of ethics, 2016. Available: https://stillmed. olympic.org/media/Document\%20Library/OlympicOrg/IOC/What-We-Do/Leading-theOlympic-Movement/Code-of-Ethics/EN-IOC-Code-of-Ethics-2016.pdf [Accessed 31 Dec 2018].

3 International Olympic Committee. Olympic agenda 2020: 20+20 recommendations, 2014. Available: https://stillmed.olympic.org/media/Document\%20Library/ OlympicOrg/Documents/Olympic-Agenda-2020/Olympic-Agenda-2020-20-20Recommendations.pdf\#_ga=2.25955325.1967117899.1546281927-1765704914. 1497027285 [Accessed 31 Dec 2018].

4 International Olympic Committee. International athletes forum, 2015. Available: https://stillmed.olympic.org/Documents/IOC_Executive_Boards_and_Sessions/ Executive_Board_Meetings/EB_decision-IAF_recommendations_12_2015.pdf\#_ga = 2.154041085.477030922.1546711674-1765704914.1497027285 [Accessed 31 Dec 2018].

5 International Olympic Committee. IOC consensus statement on sexual harassment and abuse in sport, 2007. Available: https://www.olympic.org/news/ioc-adoptsconsensus-statement-on-sexual-harassment-and-abuse-in-sport [Accessed 31 Dec 2018].

6 Mountjoy M, Brackenridge C, Arrington M, et al. International Olympic Committee consensus statement: harassment and abuse (non-accidental violence) in sport. $\mathrm{Br} \mathrm{J}$ Sports Med 2016;50:1019-29.

7 International Olympic Committee. Draw the line. Available: http://drawtheline.olympic. org/\#_ga=2.85002073.1967117899.1546281927-1765704914.1497027285 [Accessed 31 Dec 2018].

8 International Olympic Committee. Harassment and abuse in sport animation. Available: https://www.olympic.org/sha [Accessed 31 Dec 2018].

9 International Olympic Committee. Youth Olympic Games framework for Safeguarding athletes and other participants from harassment and abuse in sport. Available: file://IC:/Users/mountjm/Documents/IOC/Buenos\%20Aires/safeguarding/ENG_ IOC\%20Youth\%200lympic\%20Games\%20framework\%20for\%20safeguarding $\%$ 20athletes.pdf [Accessed 31 Dec 2018].

10 UNCRC. United nations convention on the rights of the child: resolution adopted by the general assembly. Geneva, Switzerland: United Nations, 1989.

11 Mountjoy M, Armstrong N, Bizzini L, et al. International Olympic Committee consensus statement: training the elite child athlete. Br I Sports Med 2008:42:163-4.

12 World Health Organization. Adolescent development. In: Maternal, child and adolescent health. World Health Organization, 2015.

13 Bergeron MF, Mountjoy M, Armstrong N, et al. International Olympic Committee consensus statement on youth athletic development. Br J Sports Med 2015:49:843-51

14 Brackenridge C, Kirby S. Playing SAFEAssessing the risk of sexual abuse to elite child athletes. Int Rev Soc of Sport 1997;32

15 Gervis M, Dunn N. The emotional abuse of elite child athletes by their coaches. Child Abuse Rev. 2004;13:215-23.

16 Vertommen T, Schipper-van Veldhoven N, Wouters K, et al. Interpersonal violence against children in sport in the Netherlands and Belgium. Child Abuse Negl 2016:51:223-36.

17 Alexander K, Stafford A, Lewis R. The experiences of children participating in organised sport in the UK. London, England: NSPCC, 2011.

18 Stafford A, Alexander K, Fry D. 'There was something that wasn't right because that was the only place I ever got treated like that': Children and young people's experiences of emotional harm in sport. Childhood 2015;22:121-37.

19 Tofftegard-Nielsen J. The forbidden ZONEIntimacy, sexual relations and misconduct in the relationship between coaches and athletes. Int Rev Sociol Sport 2001;36:165-82.

20 Leahy T, Pretty G, Tenenbaum G. Prevalence of sexual abuse in organised competitive sport in Australia. J Sex Aggress 2002;8:16-36.

21 Mountjoy M, Rhind DJA, Tiivas A, et al. Safeguarding the child athlete in sport: a review, a framework and recommendations for the IOC youth athlete development model. Br J Sports Med 2015;49:883-6.

22 Founders Group. International safeguards for children in sport, 2014. Available: http:// www.sportanddev.org/en/learnmore/safeguarding/ [Accessed 31 Dec 2018].

23 Glasgow RE, Vogt TM, Boles SM. Evaluating the public health impact of health promotion interventions: the RE-AIM framework. Am J Public Health 1999;89:1322-7.

24 Glasgow RE, Harden SM, Gaglio B, et al. RE-AIM planning and evaluation framework: adapting to new science and practice with a 20 -year review. Front Public Health 2019;7.

25 International Olympic Committee. Olympic charter, 2018. Available: https://stillmed. olympic.org/media/Document\%20Library/OlympicOrg/General/ES-Olympic-Charter. pdf\#_ga $=2.88105947 .1967117899 .1546281927-1765704914.1497027285$ [Accessed 31 Dec 2018] 